\title{
Hume e as Bases Científicas da Tese DE QUE Não Há AcAso No Mundo
}

\author{
Silvio Seno Chibeni \\ Universidade Estadual de Campinas
}

\begin{abstract}
Both in the Treatise of Human Nature and in the Enquiry concerning Human Understanding, Hume defends that "there is no chance in the world", and that "what the vulgar call chance is nothing but a secret and conceal'd cause". This view plays a crucial role in Hume's influential analysis of free will and moral responsibility. It functions also as a central presupposition in his discussion of miracles. However, Hume himself argued convincingly that the "maxim of causality", according to which "whatever begins to exist, must have a cause of existence" cannot be established a priori, by either intuition or demonstration. He concludes, then, that such "opinion must necessarily arise from observation and experience". In the present article I analyse this latter statement, showing, first, what was Hume detailed proposal for funding the principle of causality on experience. Given the apparent weakness of this proposal, I then speculate on what kind of firmer empirical foundation could, instead, have been given, in Hume's time, to the principle of causality, namely, the indirect support offered by Newtonian mechanics. Finally, I show how this theoretical link between experience and the principle, and also Hume's straightforward, inductive argument, were undermined by the inception of quantum physics, at the beginning of the $20^{\text {th }}$ century.
\end{abstract}

Keywords: Hume; causality; chance, determinism; Newtonian mechanics; quantum mechanics.

\section{Introdução}

A frase que dá título ao presente trabalho - "o acaso não é, em si mesmo, algo real" $(\mathrm{T} \text { 1.3.11.4 })^{1}$ — expressa uma tese à qual Hume parece ter aderido sem restrições. Ela é afirmada claramente, em versões diversas, no Tratado da Natureza Humana e reafirmada em termos igualmente inequívocos na primeira linha da seção sobre probabilidade da Investigação sobre o Entendimento Humano: "Embora não haja acaso no mundo,..." (E 6.1). Além dessas e de outras declarações explícitas, que essa era a posição de Hume fica claro pelo fato de que a importante análise da questão da liberdade e necessidade das ações humanas, feita na seção 8 desta última obra, depende de modo essencial da referida tese. Ela é também pressuposta na famosa discussão feita por Hume da questão dos milagres (E 10).

Hume caracteriza a noção de acaso como "meramente a negação de uma causa" ( $\mathrm{T}$ 1.3.11.4). Portanto, a tese da inexistência de acaso real equivale a afirmar que no mundo nada existe - nenhuma coisa, qualidade ou processo — sem uma causa.

Principia 16(2): 229-254 (2012).

Published by NEL — Epistemology and Logic Research Group, Federal University of Santa Catarina (UFSC), Brazil. 
Hume classifica essa tese como uma "máxima geral na filosofia" (T 1.3.3.1). No entanto, o próprio Hume ofereceu, no Tratado, um argumento convincente para mostrar que tal máxima não pode ser conhecida a priori, por intuição ou demonstração. Logo, essa "opinião tem necessariamente de provir da observação e experiência" ( $\mathrm{T}$ 1.3.3.9). No presente trabalho explicito o argumento de bases empíricas fornecido por Hume, procurando evidenciar sua fragilidade. Depois, defendo que o mais robusto fundamento empírico possível para a máxima, ou princípio, de causalidade é aquele mediado pelas teorias científicas, especialmente, no caso de Hume, a mecânica newtoniana. Explico ainda como esse fundamento foi solapado pela substituição dessa teoria pela mecânica quântica, no século XX, desenvolvimento esse que destruiu também o argumento mais direto fornecido por Hume. Sustento, porém, que embora hoje não seja mais razoável aderir à tese da inexistência de acaso no mundo, a teoria geral da causalidade proposta por Hume não foi substancialmente afetada, continuando a ser a melhor perspectiva filosófica para a compreensão da noção de causa e seu papel na ciência e na vida comum.

\section{O princípio de causalidade não é $a$ priori}

Hume dedica uma das primeiras seções da parte 3 do livro 1 do Tratado a refutar a opinião, então corrente, de que o princípio de causalidade teria caráter necessário, sendo conhecido a priori. São dois os argumentos de Hume. Primeiro, ele faz notar que o princípio não envolve nenhuma das quatro relações filosóficas que, dependendo somente das idéias relacionadas, são capazes de determinação intuitiva ou demonstrativa (semelhança, proporções em quantidade ou número, graus de qualquer qualidade, contrariedade). Depois, ele defende - seguindo um raciocínio amplamente aceito na época - que se o princípio de causalidade fosse intuitiva ou demonstrativamente certo, seria impossível conceber o seu contrário, ou seja, conceber que "um objeto não existe agora e existe no próximo instante, sem juntar a ele a idéia distinta de uma causa ou princípio produtivo" ( $\mathrm{T}$ 1.3.3.3). Mas isso "é claramente possível para a imaginação" (ibid.), o que mostra que a máxima da causalidade não é necessária, nem, portanto, conhecida por intuição ou demonstração.

Isso não significa, porém, que a máxima não seja verdadeira. Como já salientei, Hume não só assevera explicitamente a máxima, mas também efetivamente a usa em diversas de suas análises de tópicos relacionados. Hume precisa, portanto, indicar uma rota epistêmica alternativa capaz de fundamentar seu conhecimento. Ele o faz no final dessa mesma seção 3: "Uma vez que não é pelo conhecimento ou qualquer raciocínio científico que derivamos a opinião da necessidade de uma causa para cada produção nova, tal opinião tem necessariamente de surgir da observação e da experiência" ( $\mathrm{T}$ 1.3.3.9). O contexto não deixa dúvida de que por 'conhecimento' e 
'raciocínio científico' Hume denota, simplesmente, os processos cognitivos a priori da intuição e demonstração, geradores de conhecimento certo. Na penúltima seção deste trabalho tentarei mostrar que, ironicamente, a melhor base para a crença de Hume no princípio de causalidade é justamente algo que nós, hoje em dia, poderíamos chamar de uma espécie de "raciocínio científico". Antes, porém, as teses e argumentos de Hume precisarão ser examinados em detalhe.

\section{O princípio de causalidade não deriva diretamente da "observação e experiência"}

A questão que Hume passa a examinar é, portanto, a de "como a experiência dá origem a esse princípio" (T.1.3.3.9). Esse exame é que levará Hume ao cerne de sua teoria epistemológica da causalidade, no restante da parte 3 do livro 1 do Tratado e das seções correspondentes da Investigação. A primeira providência de Hume é reduzir a generalidade da questão, transformando-a nestas duas outras: "por que concluímos que tais causas particulares têm necessariamente tais efeitos"? e "por que fazemos a inferência de umas para outros"? Este não é o lugar para acompanhar todos os aspectos das análises humeanas desse complexo assunto. Bastará rememorar algumas das teses e argumentos centrais da teoria de Hume.

Na busca do conhecimento de causas e efeitos, Hume propõe, logo no início, antes mesmo da seção sobre o princípio de causalidade, que causas e efeitos são contíguos no espaço e no tempo e que as causas são temporalmente anteriores aos seus efeitos ( $\mathrm{T}$ 1.3.2.6 e 7). Embora diga que ambas essas condições sejam "essenciais para as causas e efeitos", Hume reconhece que ao adotar a primeira está simplesmente seguindo a "opinião geral", e que a segunda "está sujeita a controvérsias" (ibid.) Na verdade, ele não faz muita questão de defender esses pontos, tanto assim que na Investigação eles são omitidos completamente. O que realmente constitui o núcleo duro da noção de causação é uma terceira relação empírica, a conjunção constante de causas e efeitos. No Tratado a exposição desse ponto é adiada até T 1.3.6.2, enquanto que na Investigação ele é destacado logo no início da análise da causalidade (E 4.6), providência que evita que o leitor se distraia com tópicos secundários ou demasiadamente abstrusos.

Quando observamos que objetos ou eventos de dois tipos ocorrem conjuntamente em muitos casos, "chamamos um de causa e outro de efeito, sem mais cerimônias” ( $\mathrm{T}$ 1.3.6.2), ou seja, é a experiência da conjunção constante que nos informa que há uma relação causal. Antes dela, a mera observação dos objetos era totalmente incapaz de nos informar que a existência de um estava ligada à do outro: "Não há nenhum objeto que implique a existência de nenhum outro, se considerarmos esses objetos em si mesmos" ( $\mathrm{T}$ 1.3.6.1; ver também T 1.3.2.5). Além disso, quando, uma 
vez obtida essa experiência da conjunção constante, observamos novamente apenas um dos objetos relacionados, inferimos a existência do outro, "em conformidade com a nossa experiência passada" ( $\mathrm{T}$ 1.3.6.2). Uma porção importante do esforço argumentativo de Hume está em mostrar que essa inferência "não é determinada pela razão, mas por certos princípios que associam as idéias desses objetos e as unem na imaginação" ( $\mathrm{T}$ 1.3.6.12). A razão aqui referida é tanto a razão no sentido estrito - razão demonstrativa - como também a razão no sentido estendido proposto por Hume, capaz de estruturar argumentos "prováveis", i.e. relativos a questões de fato.

Do ponto de vista do conhecimento da causalidade considerada objetivamente, isso é tudo o que sabemos. Fica faltando, porém, o conhecimento de um item que Hume havia inicialmente dado como "uma relação de muito maior importância" que as de contiguidade e anterioridade temporal: a "conexão necessária" entre causas e efeitos (T 1.3.2.11). Por mais extensa e regular que seja nossa experiência da conjunção entre dois tipos de objetos, jamais percebemos, neles próprios, qualquer conexão ou poder causal. No Tratado, Hume adota a estratégia de primeiro enunciar esse importante resultado, com base em algumas considerações preliminares, deixando sua discussão para mais tarde, com a desculpa de que, tendo a busca desse conhecimento se revelado a princípio infrutífera, iria primeiro investigar em profundidade as inferências causais - mostrando que se baseiam em um mecanismo instintivo da imaginação - para depois ver se dessa investigação não resultaria o conhecimento procurado da conexão necessária. Quando, porém, o assunto é retomado, em $\mathrm{T}$ 1.3.14, não somente a busca novamente resulta vã, mas também Hume oferece novos argumentos para mostrar que esse é um resultado definitivo. Dada a importância do ponto, ao reescrever essa porção de seu texto para formar a seção 7 da Investigação tais argumentos são repetidos e complementados por diversos outros, com vistas a deixar claro que o resultado negativo vale não somente para as relações causais entre corpos, mas também entre corpos e mentes e entre os objetos da própria mente. Hume reforça e/ou generaliza, portanto, as análises do mesmo assunto feitas por seus antecessores imediatos. ${ }^{2}$

\section{Inexistência de poderes causais reais?}

Da inexistência de qualquer experiência de conexão necessária Hume poderia, por seu princípio da cópia ( $\mathrm{T}$ 1.1.1.7), haver concluído que quando empregamos a expressão 'conexão necessária' "apenas usamos palavras comuns, sem nenhuma idéia clara e determinada" ( $\mathrm{T}$ 1.3.14.14), e que portanto a expressão seria inteiramente desprovida de significado. Hume distingue, porém, o uso ordinário da expressão, em que está pressuposta sua referência a um poder real nos objetos causalmente relacionados - uso em que de fato a expressão é desprovida de significado distinto —,

Principia 16(2): 229-254 (2012). 
de um uso filosófico, elaborado por Hume a partir de sua inovadora investigação do processo mental de formação de crenças causais (ver Chibeni 2006 e 2008b). Essa investigação revelou que, ao fazermos uma inferência causal, o hábito adquirido da experiência da conjunção constante opera sobre a imaginação, de modo que a mente, na presença da impressão de um dos objetos relacionados, "sente uma determinação ... para passar de um objeto para seu acompanhante usual" (T 1.3.14.20). É da observação reflexiva dessa determinação ou impulso que a mente finalmente forma a idéia de conexão necessária. Com essa idéia a expressão recebe significado empírico genuíno.

A partir desse ponto, segue-se, em ambos os livros de Hume, uma série de intrigantes frases, que, ao menos se tomadas ao pé da letra, afirmam que não há conexões necessárias reais no mundo. Ainda em T 1.3.14.20 lemos, por exemplo:

A necessidade é, então, o efeito dessa observação, não passando de uma impressão interna da mente, ou determinação de conduzir nossos pensamentos de um objeto para outro. Se não a considerarmos desse modo, jamais alcançaremos a mais remota noção do que seja ... (T 1.3.14.20; grifos meus)

E, logo adiante:

A idéia de necessidade surge de alguma impressão. Nenhuma impressão transmitida por nossos sentidos é capaz de dar origem a tal idéia. Ela deve, portanto, ser derivada de alguma impressão interna, ou seja, de uma impressão de reflexão. A única impressão interna com alguma relação com aquilo de que estamos tratando é a propensão, produzida pelo costume, a passar de um objeto à idéia daquele que o acompanha usualmente. Tal é, portanto, a essência da necessidade. Em suma, a necessidade é algo que existe na mente, e não nos objetos. E jamais poderemos formar a menor idéia dela se a considerarmos como uma qualidade dos corpos. (T 1.3.14.22; grifo meu) ${ }^{3}$

O ponto continua sendo repetido no parágrafo seguinte:

Assim como a necessidade que faz com que dois multiplicado por dois seja igual a quatro ou que a soma dos três ângulos de um triângulo seja igual a dois retos encontra-se unicamente no ato do entendimento pelo qual consideramos e comparamos essas idéias; assim também a necessidade ou poder que une causas e efeitos está na determinação da mente a passar daquelas a estes ou reciprocamente. A eficácia ou energia das causas não se situa nem nas próprias causas, nem em Deus, nem na confluência desses dois princípios. Pertence inteiramente à alma que considera a união de dois ou mais objetos em todos os casos passados. É aqui que se encontra o poder real das causas, com sua conexão e necessidade. (T 1.3.14.23; grifos meus)

Feitas essas declarações, Hume acrescenta: "Reconheço que, de todos os paradoxos que já apresentei ou que terei ocasião de apresentar no decorrer deste Tratado, 
esse é o mais radical" ( $\mathrm{T}$ 1.3.14.24) Ao menos da forma como foi expressa nessas passagens, a conclusão de Hume seria a de que a conexão necessária ou poder causal é algo que não existe nos objetos, incluindo-se aí a própria mente, considerada objetivamente, sendo apenas a impressão subjetiva que a experiência dos objetos produz na mente, em certas circunstâncias.

Essa é uma tese metafísica e, enquanto tal, de inserção problemática numa teoria epistemológica de cunho cético, como a de Hume. Ademais, ela parece estar em tensão, quando não em contradição, com a tese da inexistência do acaso, que, como indicado preliminarmente na introdução deste artigo, e como veremos com mais detalhes logo adiante, Hume aceitou e defendeu de forma inequívoca. É, pois, importante examinar mais detidamente essa tensão, antes de avançar para outros tópicos.

Quero aqui propor duas coisas. Primeiro, que a referida tensão não é uma contradição, em sentido estrito. Depois, que de fato Hume não defendeu a primeira tese, ou seja, que ele não mantinha que os poderes causais não existiam nos objetos causalmente relacionados.

Como já vimos, Hume entendia por acaso a inexistência de causas. Portanto, as duas teses em análise só seriam contraditórias se a existência de causas fosse entendida como a existência de poderes causais reais. Nessa acepção, evidentemente Hume não poderia, sem cair em contradição, defender que não há acaso no mundo e que não há causas reais. Mas Hume é cuidadoso em distinguir claramente a noção de causa da noção de poder causal, ou, em sua expressão sinônima favorita, "conexão necessária". Isso abre espaço para a possibilidade de se entender a tese da inexistência do acaso em termos puramente empíricos, como simplesmente a existência de regularidade perfeita nas "operações da natureza"; ou, em outros termos, a tese de que para cada objeto ou evento do mundo sempre haverá outro objeto ou evento anterior e contíguo a ele que, em casos semelhantes, guarda a mesma relação de anterioridade e contiguidade com objetos do primeiro tipo. Entendida dessa forma, a tese não tem implicações diretas para a questão da existência de poderes causais reais, podendo, portanto, ser mantida qualquer que seja a posição que se assuma quanto a essa questão metafísica. Ademais, como veremos no restante deste artigo, a tese efetivamente defendida por Hume quando ele diz que não há acaso no mundo é apenas essa tese mais fraca da perfeita regularidade da natureza.

Passo agora a minha segunda tese, ou seja, que Hume não defendeu que não havia poderes causais conectando os objetos, a despeito das supracitadas frases. A primeira coisa a se notar é que, evidentemente, quando Hume fala em "conexão necessária" não se refere a uma conexão logicamente necessária. Depois das incisivas críticas de Hume e de seus predecessores imediatos, ninguém sensato continuaria pensando que há uma necessidade lógica ligando causas e efeitos. Desse modo, Hume toma a necessidade, nessa expressão, num sentido metafísico; isso, 
aliás, está implícito no seu tratamento usual das expressões 'conexão necessária' e 'poder causal' como sinônimos, como ocorre, por exemplo, no último trecho citado (T 1.3.14.23).

Portanto, se ele de fato estivesse negando, em seus comentários, que há conexões necessárias, ou poderes causais reais, ele estaria propondo que causas e efeitos são objetos ou eventos metafisicamente soltos. Disso resultaria que sua conjunção regular é inteiramente inexplicável e misteriosa! Essa conclusão absurda mostra, a meu ver, que há algo errado nessa interpretação. Alio-me, nesse ponto, à interpretação dos textos de Hume inaugurada no século XX por Norman Kemp Smith e que, no que diz respeito especificamente ao presente assunto, mantém: (a), que a posição de Hume quanto à existência ou não de poderes causais reais é um tipo de "ceticismo mitigado", segundo o qual embora não tenhamos como determinar isso com certeza, podemos formar crenças razoáveis sobre o ponto; e, (b), que Hume acreditava como qualquer homem - que esses poderes causais de fato existem.

Como, porém, essas são teses que, embora discrepantes de uma longa e respeitável tradição de interpretação, têm sido adequadamente defendidas por outros autores, serão relegadas a um apêndice ao presente texto, o que me permite passar diretamente ao seu tópico principal, as bases para a crença de que não há acaso no mundo, entendendo-se por isso a tese empírica de que há uma perfeita regularidade no curso dos fenômenos naturais.

\section{A crença na inexistência do acaso: o argumento de Hume}

Passarei agora em revista as principais frases em que Hume expressa de forma enfática sua adesão à tese da inexistência do acaso. Encontram-se, em sua maioria, distribuídas pelas seções sobre as probabilidades "de acaso" e "de causas" do Tratado ( $\mathrm{T}$ 1.3.11 e 12) e nas seções sobre probabilidade e sobre liberdade e necessidade da Investigação (E 6 e 8). A primeira ocorrência, em ordem cronológica, é a que dá título a este artigo: "o acaso não é, em si mesmo, algo real, e, para falar com propriedade, é meramente a negação [da existência] de uma causa" (T 1.3.11.4). Nessa seção nenhum argumento é dado para tal afirmação. Igualmente desacompanhada de suporte argumentativo explícito é a afirmação, também já citada, com que Hume abre a seção sobre probabilidade da Investigação. Neste caso Hume faz dois breves comentários que já indicam a direção na qual explorou o assunto em $\mathrm{T}$ 1.3.12, como veremos logo mais: "Embora não haja acaso no mundo", diz Hume, "nossa ignorância da causa real de um evento qualquer tem sobre o entendimento a mesma influência, e provoca uma espécie semelhante de crença ou opinião" (E 6.1). E mais adiante acrescenta:

Há algumas causas que produzem um certo efeito de maneira inteiramente uniforme e constante, e jamais se encontrou nenhum exemplo de falha ou

Principia 16(2): 229-254 (2012). 
irregularidade em sua operação. O fogo sempre queimou e a água sempre afogou qualquer criatura humana; a produção de movimento pelo impulso e pela gravidade é uma lei universal que até agora não apresentou exceções. Mas há outras causas que se têm mostrado mais irregulares e incertas: o ruibarbo nem sempre funcionou como um purgante ou o ópio como um soporífero para todos os que ingeriram essas substâncias. É verdade que, quando alguma causa deixa de produzir seu efeito costumeiro, os filósofos não atribuem essa ocorrência a nenhuma irregularidade da natureza, mas supõem que a operação foi frustrada por algumas causas ocultas naquela particular estrutura de partes. Nossos raciocínios, porém, e nossas conclusões relativas ao acontecimento, procedem como se esse princípio não existisse. (E 6. 4; grifo meu) ${ }^{4}$

Voltemos ao Tratado. Como já lembrei, o assunto é explorado com detalhes na seção sobre as probabilidades de causas ( $\mathrm{T}$ 1.3.12), em que Hume desenvolve uma sofisticada explicação do mecanismo de formação de crenças causais quando a experiência da conjunção de fenômenos que está na base dessas crenças não é inteiramente regular. Na verdade, essa explicação é apenas uma extensão e aplicação particular da teoria desenvolvida na seção precedente, sobre probabilidades de acaso. Não vou discutir essa explicação aqui.

O que interessa agora é apenas ver como Hume lida com o fato de que em inúmeras ocasiões não há regularidade estrita na conjunção de fenômenos naturais. A posição adotada por Hume é assumir que de fato não há irregularidade na operação das causas, e que as irregularidades observadas são um fenômeno puramente epistêmico, devido à nossa ignorância de certas superposições complexas de causas. ${ }^{5}$ Hume não dá mostras de nenhuma hesitação nem quanto à existência de uma perfeita regularidade nos processos naturais, nem quanto à capacidade de os filósofos naturais sempre descobrirem as causas secretas das aparentes irregularidades observadas. ${ }^{6} \mathrm{E}$ significativo, a esse respeito, que o parágrafo do Tratado em que apresenta sua posição de forma detalhada seja transcrito, em termos quase idênticos, na Investigação. Aqui está ele:

O vulgo, que toma as coisas segundo sua primeira aparência, atribui a incerteza dos eventos a uma incerteza nas causas, que faria com que, mesmo sem encontrar nenhum obstáculo ou impedimento à sua operação, essas causas falhassem amiúde em sua influência habitual. Mas os filósofos, observando que quase todas as partes da natureza contêm uma ampla variedade de fontes e princípios que ficam ocultos em razão de serem diminutos ou distantes, descobrem que é ao menos possível que a contrariedade dos eventos proceda, não de uma contingência na causa, mas da operação secreta de causas contrárias. Essa possibilidade se converte em certeza por ulterior observação, quando percebem que, mediante exame exato, uma contrariedade de efeitos sempre deixa transparecer uma contrariedade de causas, procedendo

Principia 16(2): 229-254 (2012). 
de sua mútua obstrução e oposição. A melhor razão que um camponês é capaz de dar para um relógio que parou de andar é dizer que comumente não funciona direito. Um artesão, ao contrário, percebe facilmente que a mesma força na mola ou no pêndulo exerce sempre a mesma influência sobre as engrenagens; mas, se seu efeito habitual falha, isso se deve talvez a um grão de poeira, que interrompe todo o movimento. Pela observação de vários casos paralelos, os filósofos formam a máxima de que a conexão entre todas as causas e efeitos é igualmente necessária, e que sua aparente incerteza em alguns casos procede da oposição secreta de causas contrárias. (T 1.3.12.5; grifo meu. Ver também E 8.13.) ${ }^{7}$

Deve-se notar que enquanto nesta seção do Tratado essa tese é apresentada como que de passagem, dado que o objetivo da seção é outro - mostrar que, quando estamos na situação de ignorância, a reação automática da mente na formação da crença (enfraquecida) é a mesma, quer tenham razão os filósofos, quer o vulgo na seção 8 da Investigação ela cumpre um papel crucial: sustentar, por analogia, ou talvez também por identidade, a tese de que não há acaso no mundo moral, ou seja, que "motivos, circunstâncias e caracteres" determinam completamente as "ações da vontade" (E 8.22). Esse é um ingrediente fundamental da teoria moral de Hume, que já nessa seção argumenta que, ao contrário do que muitos assumem, sem uma ligação necessária e uniforme não haveria lugar para imputabilidade moral.

Certamente que por estar, agora, recorrendo à tese de modo essencial, Hume decide reforçá-lo com um exemplo adicional:

Assim, por exemplo, no corpo humano, quando os sintomas usuais da saúde ou da doença frustram nossas expectativas, quando os remédios não operam com a eficácia costumeira, quando resultados irregulares decorrem de alguma causa particular, o filósofo e o médico não se surpreendem com isso, nem são tentados a negar, em geral, a necessidade e uniformidade dos princípios que dirigem a economia animal. Eles sabem que um corpo humano é uma máquina imensamente complicada, que nele se ocultam muitos poderes secretos que estão totalmente além de nossa compreensão, que ele frequentemente nos parecerá muito incerto em suas operações; e que, portanto, os eventos irregulares que se manifestam exteriormente não provam que as leis da natureza não sejam obedecidas com a máxima regularidade em suas operações e determinações internas. (E 8.14)

Logo em seguida vem o ponto que mais interessa a Hume nesse momento:

O filósofo, para ser consistente, deve aplicar o mesmo raciocínio às ações e volições de agentes dotados de inteligência. As resoluções mais irregulares e inesperadas dos seres humanos podem ser frequentemente explicadas por aqueles que conhecem cada detalhe particular de seu caráter e situação. Uma pessoa de gênio amável dá uma resposta irritada; mas é que ela tem

Principia 16(2): 229-254 (2012). 
dor de dente, ou não almoçou. Um tipo vagaroso exibe uma vivacidade incomum em suas maneiras; é que um golpe de sorte subitamente o favoreceu. [...] Os princípios e motivos internos podem operar de maneira uniforme, não obstante essas aparentes irregularidades, do mesmo modo que se supõe que os ventos, chuvas, nuvens e outras variáveis do clima são governados por princípios estáveis, embora a sagacidade e a investigação dos homens não possam facilmente descobri-los. (E 8.15)

Esse paralelo entre a filosofia natural e a filosofia moral, no que diz respeito à questão da regularidade das causas (ou de sua "necessidade"), é explorado extensamente por Hume em outras passagens dessa seção 8. Não irei me alongar sobre o assunto aqui, limitando-me a observar, como já o fiz por antecipação na Introdução, que o simples fato de ele ser traçado e usado num ponto tão central da filosofia moral de Hume indica claramente que ele de fato acreditava na inexistência do acaso, tanto num domínio como no outro; ou, nas apropriadas palavras de Filo nos Diálogos sobre a Religião Natural: "Seguramente, todas as coisas são governadas por leis estáveis e invioláveis". 8 Além disso, os trechos citados deixam claro que a base dessa crença é o sucesso da filosofia natural moderna. Esse ponto já foi, é claro, capturado por comentadores. D. Macnabb, por exemplo, diz, ao se referir ao importante parágrafo $\mathrm{T}$ 1.3.12.5: "Esse parágrafo oferece o tratamento dado por Hume para as razões que temos para aceitar a uniformidade da Natureza: simplesmente uma indução a partir do sucesso da ciência natural." ${ }^{9}$ Quão boa é essa indução? Essa a questão que abordarei na próxima seção.

\section{A crença na inexistência do acaso: o argumento baseado na mecânica newtoniana}

Quando Hume diz que, diante de irregularidades na ocorrência de fenômenos "os filósofos" - ou cientistas, como diríamos - procuram identificar partes e operações internas dos objetos envolvidos que, uma vez levadas em consideração, permitem a recuperação de uma regularidade perfeita, inegavelmente expõe um fato típico da atividade científica real. Menos certa é a opinião de Hume de que os "filósofos" não apenas buscam determinar essas causas ocultas, mas também frequentemente as encontram. É difícil mensurar a extensão do sucesso desse empreendimento científico. Esse é um tópico da mais alta relevância para a filosofia da ciência e para a epistemologia, sobre o qual, porém, aparentemente não há estudos detalhados. Parece certo que a busca explicações para as irregularidades naturais por meio da identificação, ou postulação, a título de hipóteses, de regularidades mais finas subjacentes aos fenômenos é um dos motores principais da ciência moderna e contemporânea, e que o grau de êxito dessa busca depende muito da área de investigação e de cada 
caso particular. Naturalmente, a tarefa terá mais chances de sucesso quanto mais simples forem os objetos envolvidos; de forma que a esperança de Hume de que ela poderia ser empreendida mesmo na área da "natureza humana" é, em grande parte, exagerada, dada a complexidade do homem, como ser moral. Quando, pois, ele fundamenta a sua crença na determinação estrita da vontade pelos motivos, circunstâncias e caracteres numa analogia com os fenômenos do mundo físico ele faz uma aposta bastante alta no poder da ciência - tanto das ciências naturais, como da sua própria "ciência da natureza humana", cabendo-nos o direito de não fazer a mesma aposta. Mas esse não é o ponto central da presente análise.

Quero simplesmente defender que, no que diz respeito especificamente às ciências naturais, a observação de Macnabb, embora vá na direção correta, é apenas parte da estória. Embora o que os textos de Hume explicitamente mencionem seja de fato um tipo de extrapolação indutiva a partir de alguns casos bem-sucedidos, uma reconstrução racional do ponto poderia, e deveria, levar em conta também que havia, à época de Hume, uma teoria muito bem estabelecida capaz de fundamentá-lo: a mecânica newtoniana. Essa teoria fornecia, o referencial básico de compreensão do mundo físico, não apenas em sua área específica, mas em todas as áreas das ciências naturais, dada a aceitação geral da perspectiva mecanicista, segundo a qual tudo o que ocorria no mundo físico tinha, em última instância, uma causa mecânica.

A teoria mecânica de Newton envolve duas noções fundamentais, a de estado e a de leis dinâmicas. O estado de um corpo é a sua caracterização básica, a partir da qual as demais propriedades dinâmicas do corpo decorrem dedutivamente, ou por definição. No caso, o estado de um corpo simples (uma "partícula") é dado pelo par $(x, p)$, onde $x$ é a posição do corpo e $p$ o seu momentum (massa vezes velocidade). Levando-se em conta que essas grandezas são tridimensionais, temos, então, que o estado é um conjunto de seis números. Para um corpo composto, o estado é dado pelo estado de cada uma de suas partículas (sendo que a subdivisão do corpo em "partículas" não precisa, necessariamente, ser um processo real).

Tipicamente, o estado de um corpo muda com o tempo; as leis dinâmicas especificam justamente como essa mudança se dá, em função das forças que atuam sobre ele. Detalhes à parte, o que nos interessa aqui é que a evolução do estado de um corpo newtoniano é estritamente determinista, ou seja, dado o estado inicial e as forças que atuam, fica em princípio determinado o seu estado em qualquer outro instante do tempo. O fato de que nem sempre, ou quase nunca, sejamos na prática capazes de fazer essa previsão não interfere com o que acaba de ser dito, ou seja, que segundo a visão de mundo dessa teoria todos os processos mecânicos - e portanto, segundo a concepção mecanicista, todos os processos físicos — são determinados estritamente por causas antecedentes.

Ora, isso é, em palavras diferentes, exatamente o que Hume caracterizou como a máxima ou princípio de causalidade, entendido como a afirmação da operação 
estritamente regular da natureza. Nesse sentido, o princípio descreve a realidade física como consistindo de entes que formam uma grande máquina, que funciona segundo leis estritas, segundo as quais tudo o que acontece está correlacionado a entes e eventos antecedentes. Nesse nível, há uma identidade entre a perspectiva estabelecida pela mecânica newtoniana e a visão de mundo defendida por Hume. Agora é importante notar que nada nessa visão envolve teses metafísicas específicas sobre o que faz com que o mundo exiba essa regularidade estrita. Ela pode ser entendida como provindo de poderes causais dos próprios corpos, ou de poderes exclusivamente mentais (como em Berkeley), ou de poderes exclusivamente divinos (como em Malebranche). Como Hume mostrou, não temos como determinar isso com certeza; mas daí não se segue que a tese da regularidade geral do mundo não possa ser mantida.

Ao contrário das teses metafísicas específicas sobre a natureza dos poderes causais, esta última tese pode receber algum tipo de suporte empírico. Macnabb pensou nesse suporte como sendo simplesmente indutivo - uma meta-indução sobre o sucesso das ciências naturais. Eu estou sugerindo que ele pode também ser mediado por teorias; no caso, a teoria mecânica de Newton. Parece-me que esse suporte empírico indireto é mais robusto do que o suporte indutivo, que depende, como tentei indicar, de uma boa dose de otimismo quanto ao sucesso dos filósofos naturais em efetivamente encontrarem regularidades no mundo físico. Exceto em casos muito simples, esse sucesso nunca foi satisfatoriamente exibido, como alguns dos exemplos do próprio Hume deixam claro: a ação de medicamentos sobre o corpo humano, ou a previsão do tempo.

Retrospectivamente, podemos ver, então, que Hume teria boas razões teóricas para manter a tese da regularidade geral do mundo, independentemente do raciocínio indutivo particular apontado por Macnabb. Aquele tipo de raciocínio pode, aliás, ser visto como fornecendo suporte à própria teoria mecânica de Newton, já que cada caso de sucesso na redução de irregularidades a regularidades subjacentes pode ser entendido como uma confirmação do determinismo embutido na teoria. Mas essa teoria não está na dependência exclusiva de casos dessa espécie; seu suporte empírico provém de vários outros tipos de vínculos bem sucedidos com a realidade experimental.

\section{As bases científicas da crença na inexistência do acaso solapadas pela física quântica}

Pois bem: essas razões teóricas para a tese da inexistência de acaso no mundo perderam-se, ao menos parcialmente, com o advento da física quântica. Sob a pressão de novos fenômenos e fatores de ordem teórica, a mecânica newtoniana foi 
substituída por outras teorias, nas primeiras décadas do século XX. No que diz respeito à questão presentemente em análise, o foco deve dirigir-se à teoria que ocupou seu lugar na descrição da estrutura da matéria. Essa teoria foi formulada (na versão não-relativista) em meados dos anos 1920, sendo chamada de mecânica quântica (MQ). Nela, altera-se radicalmente tanto a caracterização dos estados dos objetos físicos como a lei dinâmica que dá sua evolução temporal.

Quanto aos estados, o conjunto de números que dão a posição e o momentum do objeto é substituído por objetos matemáticos abstratos, denominados funções de onda (ou, mais geralmente, vetores de estado). Contrariamente ao que ocorre na mecânica newtoniana, em que a especificação do estado de um sistema permite o cálculo dos valores de todas as grandezas dinâmicas do objeto (energia cinética, momento angular, etc.), a especificação completa de um estado quântico só permite a previsão dos valores de parte dessas grandezas; para as demais, a teoria fornece apenas a probabilidade de sua ocorrência, em medidas efetuadas sobre o objeto. Quando uma determinada grandeza não tem seu valor definido pelo estado quântico do objeto, uma medida dessa grandeza fornece um resultado aleatório. Nada na teoria permite sua previsão. Nesse sentido pode-se dizer que a MQ é uma teoria indeterminista, já que os resultados das observações de certas grandezas de qualquer objeto nunca são todos determinados, mesmo quando presentemente conhecemos perfeitamente o estado quântico em que ele se encontra.

Olhando esse fato do ponto de vista da evolução de estado, deve-se ressaltar que a teoria tem uma lei de evolução, a equação de Schrödinger, que é determinista. Mas, diferentemente do que ocorre com as teorias clássicas, essa equação não se aplica a certos processos; em especial, não se aplica à evolução do estado do objeto quando ele é submetido a uma interação com um aparelho de medida que mede uma das grandezas que não têm o seu valor especificado pelo estado em que o objeto se encontra! Esse é um traço muito peculiar e intrigante da MQ, cuja interpretação levou a profundas divergências entre os próprios criadores da teoria. Einstein e o próprio Schrödinger consideraram esse aspecto da mecânica quântica como indicação de que a descrição da realidade fornecida pela teoria é incompleta. Bohr, Heisenberg e praticamente todos os outros se opuseram a essa interpretação, sustentando que a teoria deveria ser considerada completa, apesar de não especificar todas as propriedades mensuráveis dos objetos físicos. No preço que estavam dispostos a pagar, incluía-se a admissão do referido indeterminismo de certos processos quânticos. Essa posição rapidamente se tornou dominante, sendo usualmente chamada de interpretação "ortodoxa", ou "de Copenhague".

Detalhes sobre esse assunto complexo não cabem aqui. ${ }^{10}$ É preciso mencionar, no entanto, que, mesmo sendo uma posição desfavorecida historicamente, a interpretação de que a MQ é uma teoria incompleta suscitou, depois de algum tempo, um profícuo programa de investigação na microfísica. Em 1952 David Bohm propôs 
uma teoria alternativa à MQ que tinha como objetivo principal justamente sanar sua aparente incompletude e, por conseguinte, seu indeterminismo (Bohm 1952). Ele chamou essa teoria de "interpretação causal da mecânica quântica"; mas depois ela ficou mais conhecida como "teoria de variáveis ocultas", sendo que a expressão se aplica a qualquer teoria que, introduzindo variáveis adicionais às da MQ, procure modificar esta última teoria justamente no sentido de tornar deterministas os processos que ela dá com aleatórios. ${ }^{11}$

Temos aqui vários pontos que merecem atenção. Primeiro, qualquer que seja a avaliação que se faça dessa proposta teórica alternativa à MQ, ela pode ser vista como um esforço contemporâneo e importante de levar adiante o programa que foi bem-sucedido na física clássica, e a que Hume efetivamente apelou para manter sua visão sobre a inexistência de acaso no mundo: descobrir ou postular níveis mais finos da realidade em que se recupere a regularidade perfeita das leis da natureza.

Depois, como um dado histórico adicional, temos o fato de que, paralelamente ao desenvolvimento do programa de teorias de variáveis ocultas, foram obtidos diversos resultados teóricos e experimentais de limitação, que mostram que a implantação de uma teoria desse tipo, embora possível, exige modificações profundas em nossa visão de mundo. Em particular, John Bell mostrou, em 1964, que teorias dessa classe que sejam capazes de reproduzir as predições estatísticas da MQ para certos tipos de pares de objetos físicos correlacionados têm de ser não-locais, ou seja, contemplar a possibilidade de ações causais a velocidades superiores à da luz (Bell 1964). Uma série de experimentos realizados ulteriormente confirmaram tais predições estatísticas, tornando inescapável a não-localidade para as teorias de variáveis ocultas. ${ }^{12}$ Esse é um preço que a maioria dos pesquisadores dos fundamentos da física considera excessivo a ser pago para a reintrodução do determinismo na microfísica.

Farei agora uma análise comparada de dois conceitos-chaves envolvidos nessa discussão: os de causalidade e determinismo. Hume entendia por 'causa', em sua face empírica objetiva, "um objeto, seguido de outro, tal que todos os objetos semelhantes ao primeiro são seguidos por objetos semelhantes ao segundo" (E 7.29). ${ }^{13}$ Portanto — e essa conclusão foi explicitada por ele diversas vezes —, a regularidade entre causas e efeitos é essencial para a relação causal; sem ela, falar em causas seria impróprio. Além disso, como vimos, ele considerava que a idéia de causa envolve também a idéia de "conexão necessária"; mas esse não é um elemento identificável na nossa experiência das próprias causas, ficando, então, confinado ou ao plano subjetivo, ou ao plano metafísico. Argumentei que, independentemente da posição que se adote quanto à natureza metafísica dessa conexão, Hume acreditava que de fato há uma regularidade geral nas operações dos corpos, de forma que nada acontece sem causas. Sugeri que essa crença pode fundar-se não apenas indutivamente, pelos casos bem-sucedidos de redução de irregularidades aparentes a regularidades subjacentes, mas também na teoria fundamental do mundo físico aceita à época, 
a mecânica newtoniana, que é uma teoria determinista. Hume não usou a palavra 'determinismo' para se referir à dependência causal estrita que acreditava existir entre objetos do mundo físico (e, aliás, também do mundo moral, como vimos). Se nós a quisermos usar para tal fim, podemos, desde que tenhamos claro que com ela não acrescentamos nada de novo à discussão. O princípio de causalidade, tal qual caracterizado por Hume, inclui o determinismo, ou mesmo se identifica com ele, dependendo da interpretação adotada. ${ }^{14}$

Quando se considera o novo panorama introduzido pela MQ e pelos desenvolvimentos ulteriores na microfísica brevemente mencionados acima, pode ser necessário reexaminar essas noções. O fato de Bohm haver chamado sua teoria de "causal" é inteiramente concorde com a abordagem humeana. Sua teoria é destinada (entre outras coisas) a implantar plenamente o princípio de causalidade humeano na microfísica. De outro lado, a preferência de outros autores e comentadores dos desenvolvimentos teóricos na microfísica por usar o qualificativo 'determinista' para essa teoria talvez indique um ponto importante: sua insatisfação com a expressão bohmiana por ter, por oposição, a implicação de que a MQ seria uma teoria não-causal. Essa teoria, talvez pensem, não aboliu as causas do mundo físico. Evidentemente que isso é verdade, num sentido geral. Mas no que toca aos processos particulares mencionados anteriormente, aos quais a equação fundamental determinista da teoria não se aplica, não se pode negar que, se a teoria for completa, eles serão genuinamente casuais, e não causais.

Consideremos dois exemplos simples.

Exemplo 1: Fótons preparados de forma idêntica em uma dada fonte e enviados a um espelho semi-transparente podem, em circunstâncias específicas dadas pela MQ e confirmadas experimentalmente, ser refletidos ou transmitidos, não havendo nada em sua descrição teórica (seu estado quântico) que determine o que ocorrerá com cada fóton individual. Assim, segundo a teoria, seu comportamento ao encontrar o espelho é genuinamente aleatório.

Exemplo 2: Átomos de um certo tipo (p. ex. átomos de prata) preparados de forma idêntica numa fonte e enviados na direção de um ímã de Stern-Gerlach podem sair dele em duas direções distintas (para cima, para baixo), sendo que nada em sua descrição teórica (seu estado quântico) determina o que ocorrerá com cada átomo individual. Assim, segundo a MQ, o comportamento de cada átomo ao passar pelo ímã é genuinamente aleatório.

Exemplos semelhantes, envolvendo diferentes tipos de objetos quânticos, podem ser encontrados em abundância. Eles deixam claro que a MQ é uma teoria que, se entendida como fornecendo uma descrição completa da realidade subjacente aos fenômenos, descreve essa realidade como contendo processos casuais. Dizendo em outros termos, o mundo tal qual descrito pela quântica é um mundo em que o princípio de causalidade examinado e defendido por Hume não é verdadeiro. 
Vale a pena confrontar diretamente esses casos da microfísica com a aquilo que Hume diz na seção do Tratado intitulada "Regras pelas quais se pode julgar acerca de causas e efeitos". ${ }^{15}$ A quarta regra é:

A mesma causa sempre produz o mesmo efeito, e o mesmo efeito nunca surge senão da mesma causa. Esse princípio nós o derivamos da experiência, e é a fonte da maioria de nossos raciocínios filosóficos. (T 1.3.15.6)

Logo em seguida Hume desmembra o princípio em dois, sendo que o que interessa para o estudo do presente caso é a segunda parte, que é a sexta regra:

O seguinte princípio funda-se na mesma razão. A diferença nos efeitos de dois objetos semelhantes tem de provir da particularidade em que eles diferem. Pois como causas iguais sempre produzem efeitos iguais, quando, em um dado caso, nossa expectativa é frustrada, temos de concluir que essa irregularidade provém de alguma diferença nas causas. (T 1.3.15.8; grifo meu)

Note-se que embora o princípio básico da regra 4 possa ser visto, a seu turno, como consequência da regra 3 , que na verdade é uma regra analítica, de definição do próprio conceito de causalidade, ${ }^{16}$ Hume insiste em afirmar que o princípio é derivado "da experiência". Isso certamente enfatiza o ponto que analisamos anteriormente, de que havia, da parte de Hume, a preocupação em incorporar em sua teoria um procedimento metodológico em uso na filosofia natural, a busca de regularidades entre os fenômenos da natureza. O sucesso, ainda que parcial, dessa busca indubitavelmente é o que está por trás da própria definição humeana da relação causal como sendo, em sua face empírica objetiva, a conjunção constante entre fenômenos do mesmo tipo. Aliás, foi o próprio Hume que muitas vezes enfatizou que se não houvesse esse tipo de experiência jamais ninguém formaria nenhuma idéia de causalidade.

Voltando ao confronto com a MQ, os exemplos dados violam a sexta regra, e portanto a quarta, na medida em que "efeitos" diferentes (passagem ou reflexão do fóton pelo espelho, etc.) seguem-se de objetos e situações que a teoria dá como idênticos, não havendo, segundo ela, nenhuma "particularidade em que eles diferem". Dada agora a definição embutida na regra 3, somos forçados a dizer que, segundo a análise de Hume, nesses casos o fenômeno (passagem ou reflexão, etc.) não é propriamente o efeito de nenhuma causa, e sim algo que ocorre de forma inteiramente casual.

Diante disso, uma possibilidade frequentemente explorada consiste em manter que, nos casos em foco, embora o evento final envolvendo o objeto (e.g. reflexão do fóton pelo espelho) não seja determinado, ele é causado, já que o objeto não faz qualquer coisa. Evidentemente, isso só faz sentido se o termo 'causado' não tiver a acepção clássica, que é aquela destacada por Hume nas suas definições filosóficas de 
'causa' e na regra 3. Seria talvez uma causalidade entendida metafisicamente como a "produção" de algo: a reflexão do fóton pelo espelho não estava determinada a ocorrer, mas não ocorreu do nada. Haveria uma causa, mas essa causa não determinaria o efeito completamente. Nessa interpretação a causalidade deixaria de incluir o determinismo, dando lugar a que na literatura contemporânea em filosofia da física se encontrem expressões como causas probabilísticas, cunhadas para denotar essas supostas "causas" quânticas.

No que me diz respeito, tenho dúvidas sobre a razoabilidade dessa proposta de se falar em causas que não determinam. Considero preferível preservar a acepção humeana da noção de causa, junto com sua teoria geral da causalidade, mesmo diante dos desenvolvimentos teóricos e experimentais da física contemporânea. O que tais desenvolvimentos trazem de novo à análise humeana é a possibilidade de que a ciência atual desautorize o raciocínio humeano pró inexistência do acaso no mundo. Não só há fenômenos para os quais não se encontrou até agora nenhuma causa determinante - fato que oferece contra-exemplos ao raciocínio indutivo feito por Hume - , como também a nossa melhor teoria sobre tais fenômenos não estabelece tais causas, nem mesmo hipoteticamente. Portanto, hoje não parece mais razoável aceitar a tese humeana da inexistência do acaso.

Mas devo sublinhar que isso não constitui uma prova de que tal tese seja falsa, pois, como tentei brevemente indicar, a manutenção de uma visão determinista do mundo quântico continua sendo possível, mediante a adoção de uma teoria de variáveis ocultas, como a de Bohm. Essa porém é uma opção dura, não apenas pela não-localidade que deverá vir junto com o pacote teórico alternativo à MQ, mas também pelo fato de as variáveis introduzidas na teoria para recuperar o determinismo serem "ocultas", ou seja, inacessíveis à experiência de uma forma radical, que não posso explicar aqui. Isso quer dizer que, ao contrário do médico do exemplo de Hume, que procura explicar a irregularidade da ação do ruibarbo sobre o intestino do homem postulando partes microscópicas dessa planta e do corpo humano que estariam, elas sim, sujeitas a leis causais, o físico que embarque na rota alternativa à MQ não pode, razoavelmente, esperar encontrar nenhuma evidência independente para a existência de suas variáveis ocultas. ${ }^{17}$ Essa foi uma das razões preponderantes da limitadíssima aceitação da teoria pelos físicos, não obstante o inegável interesse teórico e poder heurístico de sua exploração.

$\mathrm{Se}$, portanto, adotarmos a MQ como fornecedora de nossa metafísica do mundo quântico então será inescapável a rejeição da tese da inexistência real de acaso. Rejeitada essa tese, fica seriamente comprometido o raciocínio de Hume na seção sobre liberdade e necessidade. Não teríamos mais razões científicas para manter, como ele o fez, que a volição humana está estritamente determinada por causas (motivos, circunstâncias e caracteres). Isso modifica de forma dramática o panorama da discussão desse tópico clássico da filosofia. ${ }^{18}$ Felizmente, porém, o novo cenário da ciência não 
compromete a análise humeana da causalidade em geral. Sabiamente, Hume procurou desenvolvê-la sem nunca perder de vista o solo firme da experiência, de forma que quando se aventurou em sustentar uma tese metafísica sobre a causalidade - a tese da inexistência de acaso no mundo - não o faz a partir de sua epistemologia, e sim com o apoio da melhor ciência de seu tempo. Nisso, não cabe censurá-lo de nenhum modo; ele fez o que estaremos fazendo hoje, se quisermos - como penso que devemos — rejeitar essa mesma tese.

\section{Apêndice: A questão metafísica da existência de poderes causais reais.}

Retomo neste Apêndice a questão suscitada no final da seção 4, ou seja, a de saber que posição Hume teria adotado quanto à existência de poderes causais reais. Defenderei, seguindo outros autores, que: (a), essa posição é um tipo de ceticismo mitigado, segundo o qual não temos como determinar isso com certeza, mas sem que sejamos incapazes de formar opiniões bem fundamentadas acerca do ponto; e, (b), que Hume não só acreditava - como qualquer homem — que tais poderes existem, mas também que há boas razões para essa crença.

Começarei apontando algumas passagens que apóiam a tese (a). Lembremos, inicialmente, que o objetivo explícito da seção que levou Hume a fazer as afirmações paradoxais transcritas na seção 4 era encontrar a impressão da qual a idéia de conexão necessária poderia ser formada. Essa busca revelou-se mal-sucedida, quando se buscava a impressão nos próprios objetos classificados ordinariamente como causas e efeitos, e bem-sucedida quando o foco se dirigiu para a mente que observa tais objetos. Então, como vimos, Hume advoga que o significado genuíno possível da expressão 'conexão necessária' é o que resulta desta última impressão, uma impressão de reflexão. Mas se a expressão for usada no sentido realista usual, não terá nenhum "significado distinto" ( $\mathrm{T}$ 1.3.14.14), porque seu referente pretendido é uma suposta qualidade "acerca da qual não nos é possível formar a mais remota idéia" ( $\mathrm{T}$ 1.3.14.25). Agora o ponto crucial é saber se Hume de fato nega a existência dessa qualidade, como as frases transcritas implicam, quando tomadas literalmente. Ele mesmo diz que não:

De fato, estou pronto a admitir que pode haver várias qualidades, tanto nos objetos materiais como nos imateriais, que desconhecemos completamente; e se quisermos chamá-las de poder ou eficácia, isso pouco importará para o mundo. ( $\mathrm{T}$ 1.3.14.27)

Logo depois, Hume complementa essa declaração, deixando claro que concede também que "as operações da natureza são independentes de nosso pensamento 
e raciocínio" ( $\mathrm{T}$ 1.3.14.28), sendo que entre essas operações incluem-se as mais relevantes para o assunto em tela: as relações de contiguidade e sucessão regular entre causas e efeitos. Ele objeta apenas a que "vamos além disso, e atribuamos um poder ou conexão necessária a esses objetos" (ibid.), pois só estaríamos autorizados a fazê-lo se pudéssemos observar tal poder - o que não podemos, como ele e outros bem mostraram. Portanto, com base unicamente em nossa experiência direta de causas e efeitos não podemos nem afirmar nem negar que poderes causais existam nos objetos causalmente relacionados.

Essa conclusão cética se reflete nos comentários que Hume tece relativamente às duas famosas definições de causa, que oferece logo em seguida. A objeção de que as definições são "defeituosas, porque tiradas de objetos estranhos à causa" (pois provêm da observação da mente de quem observa a causa, e não da própria causa) é concedida por Hume, que, com total sinceridade, diz não conhecer nenhum "remédio" para esse defeito ( $\mathrm{T}$ 1.3.14.31) Ora, se a noção de causalidade se esgotasse na mera conjunção constante e impulso da mente as definições evidentemente não seriam "defeituosas".

Além de declarações explícitas como essas, há algumas considerações adicionais que reforçam a interpretação cética que estou defendendo. Primeiro, há, é claro, o fato de que não só quanto aos poderes causais mas também sobre vários outros pontos - existência dos corpos, existência de Deus, etc. — o próprio Hume explora e estende argumentos céticos já disponíveis, acrescentando outros novos.

Depois, as declarações aparentemente negativas - e portanto não-céticas — que faz sobre a existência de poderes causais reais ou conexões necessárias são feitas a título de comentários, com possível intenção retórica; mas ao longo do trabalho duro de análise da nossa cognição da relação causal que ele fez no Tratado e, principalmente, na Investigação, o que vemos são, apenas, argumentos que mostram que não conhecemos, nessa relação, um dos ingredientes, a "conexão necessária".

Por fim, no final da seção 7 deste último livro, após esse trabalho argumentativo exaustivo, ele comenta as posições de alguns de seus antecessores, para indicar falhas na posição não-cética que por vezes assumiram sobre a natureza metafísica da causalidade. O caso que mais nos interessa agora é o de Malebranche, que defendia que a única fonte de poder causal no mundo era Deus. Nem corpos nem mentes criadas teriam nenhum poder causal. Duas das críticas de Hume a essa doutrina merecem ser relembradas. A primeira é a de que ao "destituir a Natureza e todos os seres criados de todo poder causal" Malebranche estaria de fato rebaixando a divindade, ao invés de realçá-la (como ele pretendia). Essa é uma crítica claramente ad hominem, mas nem por isso deixa de ser relevante. A segunda crítica é mais direta: incide sobre a inferência que vai da ignorância dos poderes causais nos objetos (corpos e mentes) - ignorância essa com a qual Hume concorda — para a inexistência desses poderes. Hume rejeita essa inferência de modo inequívoco: 
Ignoramos, é verdade, o modo pelo qual os corpos operam uns sobre os outros. Sua força e energia nos são inteiramente incompreensíveis. Mas porventura não ignoramos igualmente a maneira ou a força pela qual a mente, mesmo a mente suprema, opera sobre si mesma ou sobre o corpo? [...] Assim, se nossa ignorância fosse uma boa razão para rejeitar alguma coisa, seríamos levados por esse princípio a negar toda energia ao Ser Supremo, tanto como o fizemos com relação à matéria mais bruta, pois certamente entendemos tão pouco das operações envolvidas em um caso como no outro. (E 7.25; grifos meus.)

Diante de palavras tão claras, seria insensato continuarmos pensando que o próprio Hume teria cometido essa falácia, de inferir que algo não existe (os poderes causais reais em geral) pelo fato de não ser conhecido, no sentido estrito do termo 'conhecer'.

Passo agora à tese (b), de que Hume de fato acreditava que há poderes causais ligando cada objeto do mundo a certas causas. O termo é bem este: crença. Não se trata de conhecimento, no sentido estrito adotado pelos modernos, de conhecimento certo. A existência de tais poderes não pode ser provada a priori, nem ser estabelecida por experiência direta. Isso não implica, porém, que sua existência não possa ser objeto de crença. Uma das grandes contribuições de Hume para a epistemologia consistiu justamente em aprofundar o insight de Locke, no sentido de tratar a crença como uma categoria epistêmica respeitável, complementar à do conhecimento. Hume desenvolveu pioneiras e sofisticadas explicações dos mecanismos de formação de crença em três casos importantes, as crenças causais, a crença na existência dos corpos e crença na permanência e identidade do eu — crenças que, enquanto fenômenos da natureza humana, Hume achava descabido negar que existissem. $^{19}$

A interpretação dessas teorias da formação de crenças naturais é objeto de polêmica, havendo uma oposição entre aqueles que pensam que elas cumprem papel meramente descritivo da mente humana e os que, seguindo os passos de Kemp Smith (1905, 1941), vêm defendendo que também têm relevância epistemológica. ${ }^{20}$ Este artigo não se destina a explorar o debate em profundidade. Quero apenas relembrar, para o caso das crenças causais, os fundamentos gerais da explicação dada por Hume. Na verdade, a teoria de Hume explica duas coisas: a crença de que as regularidades observadas se estendem também aos casos semelhantes ainda não observados, e a crença de que essas regularidades se devem à existência de certos poderes nos objetos relacionados. A primeira dessas crenças radica, segundo Hume, no hábito que se forma na mente exposta à conjunção regular de dois tipos de objetos ou eventos. A crença na realidade de poderes causais reais, inerentes aos objetos causalmente relacionados, provém de uma natural "propensão [da mente] a se espalhar pelos objetos externos, ligando a eles todas as impressões internas que eles ocasio- 
nam, e que sempre aparecem ao mesmo tempo em que esses objetos se manifestam aos sentidos" ( $\mathrm{T}$ 1.3.14.25).

Ambas essas explicações podem ser classificadas de psicológicas, e certamente esse seu caráter alimenta a interpretação tradicional, de que Hume, como filósofo, não reconhecia méritos epistêmicos nas crenças em questão, embora, como qualquer homem, se visse conduzido a elas por mecanismos instintivos e incontroláveis da mente humana, conforme explicado pela teoria de Hume. Inegavelmente, essa teoria não se dirige ao problema metafísico da existência de poderes causais reais, nem tampouco ao problema da legitimação racional da extrapolação das regularidades observadas para novos casos. Pode, não obstante, contribuir para a análise desses problemas, ao deixar claro que as crenças causais, não sendo estabelecidas com base em argumentos (como tradicionalmente se acreditava), também não podem ser criticadas com base em argumentos. Constitui, portanto, um erro manter que Hume entrou no debate de argumentos de seus predecessores e refutou, dessa forma, tanto a crença na existência de poderes causais como nas inferências causais (contemporaneamente, e equivocadamente, chamadas de "indutivas"). Na verdade, a grande contribuição de Hume para o debate foi tê-lo identificado como irremediavelmente insolúvel, propondo sua substituição por uma série diferente e original de questões, que mesclam de forma instigante o estudo empírico do funcionamento da mente humana com temas tradicionais da epistemologia.

Embora não haja acordo entre os especialistas de que essa é a interpretação correta da filosofia de Hume acerca da causalidade, considero frutífera sua exploração. Em particular, penso que devemos levar adiante a sugestão de alguns dos seus defensores de que embora as duas crenças causais de que estamos tratando não sejam passíveis de receberem suporte racional ou empírico direto, podem ser em alguma medida justificadas indiretamente, com base em considerações de nível filosófico superior. Assim, por exemplo, Kemp Smith (1941) e Louis Loeb (2002), entre outros, defenderam com bastante engenhosidade que, ao contrário de várias outras crenças (por exemplo, as que derivam, nas palavras de Hume, da "educação"), as crenças causais - ou, mais especificamente, as crenças nas regularidades causais - têm um lastro empírico evidente, justamente a observação passada dessas regularidades, e que isso, conferindo-lhes estabilidade e universalidade, seria suficiente para legitimá-las epistemicamente. Quanto à questão dos poderes causais, há, por exemplo, análises como as de Galen Strawson (1989), que argumentou - a meu ver de forma convincente - que a existência de poderes causais reais ligando os objetos é a melhor explicação para o fato de se apresentarem à nossa experiência em conjunção regular. Strawson procurou mostrar ainda, apontando e comentando diversas passagens dos textos de Hume, que essa era a sua posição filosófica, e não simplesmente a posição que qualquer homem comum implicitamente mantém, dados os mecanismos automáticos da mente identificados por Hume. ${ }^{21}$ 


\section{Referências}

Aspect, A.; Dalibard, J.; Roger, G. 1982. Experimental test of the Bell's Inequalities using time-varying analizers. Physical Review Letters 49(25): 1804-7.

Bell, J. S. 1964. On the Einstein Podolsky Rosen paradox. Physics 1: 195-200.

Bohm, D. 1952. A suggested interpretation of the quantum theory in terms of "hidden variables" - I e II. Physical Review 85(2): 166-79 e 180-93.

Chibeni, S. S. 1991. A incompletude da mecânica quântica. O Que Nos Faz Pensar 5: 89-113.

- 1992. Implicações filosóficas da microfísica. Cadernos de História e Filosofia da Ciência, Série 3, 2(2): 141-64.

—. 1995. A microfísica e a não-localidade. In: F. R. R. Évora (ed.) Espaço e Tempo. (Coleção CLE, v. 15.) Campinas, Centro de Lógica, Epistemologia e História da Ciência, pp. 187-206.

- 1997. Aspectos da Descrição Física da Realidade. (Coleção CLE, v. 21.) Campinas: Centro de Lógica, Unicamp,

- 1999. Le réalisme scientifique face à la microphysique. Revue Philosophique de Louvain 97(3-4): 606-27.

- 2001a. Indeterminacy, EPR and Bell. European Journal of Physics 22: 9-15.

—. 2001b. A interpretação da mecânica quântica. Com Ciência (SBPC/Labjor), maio de 2001.

- 2004. Ontic vagueness in microphysics. Sorites 15: 29-41.

- 2004. Holism in microphysics. Epistemologia (Itália), 27(2): 227-44.

- 2005a. Certezas e incertezas sobre as relações de Heisenberg. Revista Brasileira de Ensino de Física 27(2): 181-92.

- 2005b. A logico-conceptual analysis of the Einstein-Podolsky-Rosen argument. In: M. Pietrocola e O. Freire Jr. (eds.) Filosofia, Ciência e História: Michel Paty e o Brasil, uma homenagem aos 40 anos de colaboração. São Paulo, Discurso Editorial, pp. 115-35.

- 2006. Hume e as crenças causais. In: Ahumada, J., Pantalone, M. e Rodríguez, V. (eds.) Epistemología e Historia de la Ciencia, v. 12. (Selección de trabajos de las XVI Jornadas de Epistemología e Historia de la Ciencia.) Córdoba: Universidad Nacional de Córdoba, pp. 143-49.

- 2008a. Berkeley: uma física sem causas eficientes. Cadernos de História e Filosofia da Ciência, Série 3, 18(2): 357-90.

- 2008b. As inferências causais na teoria epistemológica de Hume. In: R. A. Martins, C. C. Silva, J. M. Hidalgo Ferreira e L. A. Pereira Martins (eds.) Filosofia e História da Ciência no Cone Sul. Seleção de Trabalhos do $5^{\circ}$ Encontro da AFHIC. Campinas: Associação de Filosofia e História da Ciência do Cone Sul (AFHIC), pp. 423-30.

- 2010. Berkeley e o papel das hipóteses na filosofia natural. Scientiae Studia 8(3): 389-419.

Craig, E. 1987. The Mind of God and the Works of Man. Oxford: Clarendon Press.

Hume, D. 1999. An Enquiry concerning Human Understanding. T. L. Beauchamp (ed.) Oxford: Oxford University Press.

- 1999. Investigação sobre o Entendimento Humano. Trad. José Oscar de A. Marques. São Paulo: Edunesp. 
2000. A Treatise of Human Nature. D. F. Norton and M. J. Norton (eds.) Oxford:

Oxford University Press.

- 2000. Tratado da Natureza Humana. Trad. Déborah Danowski. São Paulo: Edunesp.

- 1947. Dialogues concerning Natural Religion. Ed. N. Kemp Smith. 2nd ed. London: Collier Mcmillan.

Kemp Smith, N. 1905. The naturalism of Hume. Mind 14: 149-73 e 335-47.

. 1941. The Philosophy of David Hume. London: Macmillan.

Loeb, L. E. 2002. Stability and Justification in Hume's Treatise. Oxford: Oxford University Press.

Macnabb, D. G. C. 1962. Editor's notes. Hume: A Treatise of Human Nature, Book One. Glasgow: Fontana/Collins.

Millican, P. 2010. Hume's determinism. Canadian Journal of Philosophy 40(4): 611-42.

Monteiro, J. P. 1981. Hume's conception of science. Journal of the History of Philosophy 19: $327-42$.

- 1984. Hume e a epistemologia. Lisboa: Imprensa Nacional.

- 2003. Novos estudos humeanos. São Paulo: Discurso Editorial.

Newton, I. 1934. Mathematical Principles of Natural Philosophy. A. Motte (transl.) and F. Cajori (ed.) Berkeley and Los Angeles: University of California Press.

Popper, K. R. 1972. Of clouds and clocks. In: Objetive Knowledge. Oxford: Clarendon Press, cap. 6 , pp. 206-55.

Strawson, G. 1989. The Secret Connexion. Oxford: Clarendon Press.

Wright, J. P. 1983. The Sceptical Realism of David Hume. Minneapolis: University of Minnesota Press.

Winkler, K. 1991. The New Hume. Philosophical Review 100(4): 541-79.

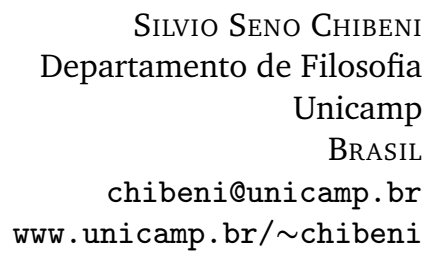

Resumo. Tanto no Tratado da Natureza Humana como na Investigação sobre o Entendimento Humano, Hume mostra-se convencido de que "não há acaso no mundo", e que "aquilo que o vulgo chama de acaso não passa de uma causa secreta e escondida". Essa tese desempenha papel crucial em sua análise do livre-arbítrio e, conseguintemente, da responsabilidade moral; é também um elemento importante em sua discussão sobre os milagres. No entanto, o próprio Hume ofereceu, no Tratado, um argumento convincente para mostrar que o princípio de causalidade, segundo o qual tudo o que começa a existir tem uma causa, não pode ser conhecido a priori, por intuição ou demonstração. Logo, essa "opinião tem necessariamente de provir da observação e experiência". O presente trabalho examina essa tese, mostrando, inicialmente, qual era a proposta de Hume para fundar na experiência o princípio de causalidade, e depois qual, de fato, teria sido o mais robusto fundamento para esse princípio: a mecânica newtoniana. Explica-se, por fim, como esse fundamento empírico indireto e o próprio argumento de Hume foram solapados pela física quântica, no século XX.

Principia 16(2): 229-254 (2012). 
Palavras-chave: Hume, causalidade, acaso, determinismo, mecânica newtoniana, mecânica quântica.

\section{Notas}

${ }^{1}$ Adotarei aqui a notação das edições do Treatise of Human Nature e da Enquiry concerning Human Understanding citadas na lista de referências bibliográficas deste texto, segundo a qual 'T x.y.w.z' denota Treatise, livro x, parte y, capítulo w, parágrafo z, e 'E r.t' denota Enquiry, capítulo $\mathrm{r}$, parágrafo $\mathrm{t}$.

${ }^{2}$ Berkeley argumentou que não percebemos poderes causais entre os corpos e que tais poderes de fato não existem neles, mas apenas em seres pensantes: Deus e espíritos criados. Malebranche, a seu turno, concordou com Berkeley quanto à inexistência de poderes causais nos corpos, mas estendeu essa tese aos espíritos criados, atribuindo a Deus a fonte exclusiva de todo poder causal. Hume defendeu que os poderes causais são imperceptíveis em todos os três casos, mas, ao contrário de Berkeley e Malebranche, não defendeu a sua inexistência em nenhum deles, como argumentarei na próxima seção e no Apêndice deste artigo.

${ }^{3}$ Nessa e em algumas outras citações mais extensas do Tratado utilizei, com pequenas adaptações, a tradução de Débora Danowski, publicada pela Edunesp.

${ }^{4}$ Nesta e em outras citações mais extensas da Enquiry, utilizei, com pequenas adaptações, a tradução de José Oscar de A. Marques, publicada pela Edunesp.

${ }^{5}$ Essa posição é semelhante à adotada por outros filósofos que se ocuparam do problema antes de Hume. Berkeley, por exemplo, embora entendesse que a fonte direta de toda regularidade natural era Deus, e admitisse que Deus pode decidir a qualquer momento produzir um milagre, ou seja, a quebra de uma regularidade natural, reconheceu, em termos explícitos, que, ao encontrar uma irregularidade o cientista trata, tipicamente, de descer a níveis mais finos de análise dos objetos envolvidos, em busca de leis mais gerais que expliquem tanto as regularidades como as irregularidades observadas. Para uma análise desse ponto, ver Chibeni 2008a.

${ }^{6}$ É útil rememorar aqui, em conexão com o que foi dito na nota de rodapé precedente, o conteúdo central da seção sobre milagres, incluída na Investigação (E 10). Embora Hume não pretenda haver demonstrado que milagres não existem - pela razão geral de esta ser uma questão de fato, e questões de fato não poderem ser objeto de demonstrações - , ele argumenta que para cada relato de suposto milagre podemos opor uma "prova" contrária, entendendo-se o termo 'prova' no sentido peculiar definido por Hume, ou seja, evidência empírica de completa regularidade causal. Esse argumento central de Hume perde parte de sua força, face às análises deste artigo.

${ }^{7}$ A tese central deste importante parágrafo é antecipada por Hume já no primeiro parágrafo da seção: "os filósofos normalmente admitem que aquilo que o vulgo chama de acaso não é senão uma causa secreta e oculta" (T 1.3.12.1).

${ }^{8}$ DNR, parte VI, p. 174. Vale a pena transcrever um trecho mais longo: "Como as coisas poderiam ser como são, se não houvesse na mente ou na matéria um princípio original e inerente de ordem? [...] Não há nenhum lugar para o acaso, sob nenhuma hipótese, cética ou religiosa. Seguramente, todas as coisas são governadas por leis estáveis e invioláveis. E se a mais íntima essência das coisas fosse exposta a nós, descobriríamos uma cena acerca

Principia 16(2): 229-254 (2012). 
da qual atualmente não temos nenhuma idéia. Ao invés de admirar a ordem dos seres naturais, veríamos claramente que é absolutamente impossível para eles assumir qualquer outra disposição, em seus mínimos detalhes." Em sua edição dos Diálogos, Kemp Smith indica, numa nota (p. 174, n. 5), que a frase que grifei era, originalmente: "É ridículo manter que há acaso, sob qualquer hipótese" ("Chance it is ridiculous to maintain on any hypothesis.") Depois, antes de chegar à sua versão final, foi alterada para "O acaso, ou, o que é a mesma coisa, a liberdade, parece não ter lugar sob nenhuma hipótese, cética ou religiosa." ("Chance, or what is the same thing liberty, seems not to have place on any hypothesis, sceptical or religious.")

${ }^{9}$ D. G. C. Macnabb, nota à p. 365 de sua edição do livro 1 do Treatise. Uma defesa extensa dessa interpretação pode ser encontrada em Millican 2010. Esse artigo apresenta diversos pontos em comum com o presente trabalho.

${ }^{10}$ Para tanto, remeto o leitor a Chibeni 1991, 1992, 1995, 1997, 1999, 2001a, 2001b, 2004, 2005a e 2005b, em que são fornecidas referências aos trabalhos originais relevantes.

${ }^{11}$ Surgiram depois propostas de se conceber teorias de variáveis ocultas em que não há determinismo completo; mas esse assunto não pode ser analisado aqui. Ver Chibeni 1997 para uma discussão detalhada.

${ }^{12}$ Ver Aspect et al. 1982 para o relato do mais importante desses experimentos.

${ }^{13}$ Essa é a definição "filosófica" de causa, encontrada também no Tratado: "Um objeto anterior e contíguo a outro, tal que todos os objetos semelhantes ao primeiro mantêm relações semelhantes de anterioridade e contiguidade com os objetos semelhantes ao último" (T 1.3.14.31).

${ }^{14} \mathrm{Na}$ interpretação realista que eu estou favorecendo neste artigo, o princípio contém algo mais que o determinismo: justamente a suposição metafísica razoável de que aquilo que faz com que tudo no mundo seja determinado (na hipótese de o determinismo ser verdadeiro) são certos poderes causais reais. Nessa interpretação a noção de causação contém, pois, um aspecto explicativo, ausente na noção de determinismo, que é o mero enunciado de uma correlação estrita entre objetos e eventos do mundo.

${ }^{15}$ Certamente, quando Hume concebeu essa seção ele tinha presentes as "Regras de raciocínio em filosofia”, que, na segunda edição dos Principia (1713), Newton inseriu no início do livro III. A as regras I e II são regras sobre causas naturais, entendidas num sentido físico robusto: Regra I: "Não se devem admitir mais causas para as coisas naturais do que as que sejam verdadeiras e suficientes para explicar as aparências." Regra II: "Portanto, aos mesmos efeitos naturais devemos, tanto quanto possível, atribuir as mesmas causas." Esta última corresponde, como se notará, a uma das partes da regra 4 de Hume (a parte menos relevante para a presente discussão).

16 "Tem de haver uma união constante entre causa e efeito. E é principalmente essa qualidade que constitui a relação." (T 1.3.15.5; grifei)

${ }^{17}$ Em seus artigos originais, de 1952, Bohm chegou a pensar nesse tipo de evidência, e por tal motivo abriu espaço em sua teoria para a eventual incorporação da efetiva disponibilização empírica das variáveis ocultas — que nada mais são, no seu caso, do que as posições dos objetos quânticos. Mas essa possibilidade foi sendo aos poucos deixada de lado, por razões que não vem ao caso comentar aqui, e hoje não é mais considerada uma alternativa viável.

18 Curiosamente, esse tópico fascinante na fronteira da ciência com a filosofia tem sido relativamente pouco explorado na literatura. Uma das exceções parece ser a conferência proferida 
por Popper em 1965, sob o título "Of clouds and clocks" (Popper 1972). Nela, Popper extrai essencialmente as mesmas conclusões filosóficas gerais que estou indicando neste trabalho, e fornece uma série de instigantes sugestões de desenvolvimento ulterior do tema.

19 Deve-se notar que no terceiro desses casos a explicação inicialmente dada por Hume, em $\mathrm{T}$ 1.4.6, é criticada pelo próprio Hume, no Apêndice (publicado um ano depois do livro 1), sendo que nessa ocasião ele confessa não possuir ou conhecer nenhuma outra explicação viável para a crença na identidade do eu (T, Apêndice, parágrafos 10-21).

${ }^{20}$ Entre os trabalhos mais importantes desta última abordagem estão Wright 1983, Craig 1987, Strawson 1989 e Monteiro 1981, 1984 e 2003. Uma crítica importante a esse "Novo Hume" é desenvolvida em Winkler 1991.

${ }^{21}$ Uma primeira versão deste artigo foi apresentada no XIV Encontro da Anpof, Águas de Lindóia, 4 a 8 de outubro de 2010, GT de Filosofia da Ciência.

Principia 16(2): 229-254 (2012). 